\title{
2
}

\section{Disability Law and the Process for Determining Whether a Student Has a Disability}

Elisa P. Laird and Gregory A. Moorehead

\section{INTRODUCTION}

This chapter first addresses what a disability is and how to determine whether someone meets the legal definition of a person with a disability. It explains the Americans with Disabilities Act (ADA) and other applicable laws, to help administrators and disability office personnel understand their obligations, including a diagram to guide the decision-making process for determining a student's disability status. Specific examples from the health sciences are provided.

\section{A BRIEF HISTORY OF DISABILITY RIGHTS LAWS}

Societal perceptions of disability have shifted over time. The medical model of disability is based on the notion that disabilities are a physical or mental deficiency and that the individual with disabilities should be "fixed" or otherwise conform to society's definition of normal (Finkelstein, 1993). This model 
also assumes that people with disabilities will never be full participants in society. Although the now-outdated medical model is still very much present, the social model of disability has become the more widely accepted model. Developed in the 1970s and 1980s, the social model asserts that it is society's environmental, cultural, and attitudinal barriers, as opposed to a person's individual impairments, that prohibit people with disabilities from participating fully in all aspects of society (Oliver, 1996). The social model encourages society to accept disability as another form of human diversity and to develop societal structures and programs that accommodate all forms of disability by design. This approach reduces the need for individualized accommodations. The introduction of the social model informed the development of civil rights laws for individuals with disabilities. Further extensions of the social model, including the cultural, relational, and minority models, have been proposed by disability scholars (Goodley, 2017).

The passage of Section 504 of the Rehabilitation Act of $1973^{1}$ and the ADA in $1990^{2}$ created broad protections for individuals with disabilities, including mandating that postsecondary education institutions remove barriers for, eliminate discrimination against, and facilitate inclusion of students with disabilities. The laws also provide individuals with the right to sue if they are discriminated or retaliated against on the basis of their disability or perceived disability. The ADA Amendments Act (ADAAA) was passed in 2008, largely to address the effects of a series of court decisions that had increasingly limited the law's scope since its enactment, particularly with regard to what constitutes a disability. The result of the 2008 amendments to the ADA was a substantial increase in the number of individuals entitled to disability protections under the law and therefore more students in higher education qualifying for disability accommodations than ever before.

\section{THE UNIVERSITY'S LEGAL OBLIGATIONS TO STUDENTS WITH DISABILITIES}

The ADA states, "No qualified individual with a disability shall, by reason of such disability, be excluded from participation in or be denied the benefits of the services, programs, or activities of a public entity, or be subjected to discrimination by any such entity." ${ }^{3}$ It has a similar provision applying to private colleges. ${ }^{4}$ It requires that institutions of higher education make modifications to their policies, practices, and procedures that would otherwise deny equal access to students with disabilities, unless doing so would result in a fundamental alteration of the services provided. ${ }^{5}$ This means

\footnotetext{
129 U.S.C. $\S 794$, et seq.

${ }^{2} 42$ U.S.C. $\S 12101$, et seq.

${ }^{3} 42$ U.S.C. $\S 12132$.

${ }^{4} 42$ U.S.C. $\S 12182(\mathrm{a})$.

${ }^{5} 42$ U.S.C. $\S 12182(\mathrm{~b})(2)(\mathrm{A})(\mathrm{ii}) ; 28$ C.F.R. $\S 36.302(\mathrm{a})$.
} 
that the law does not ask schools to lower their educational standards, but rather to provide for reasonable flexibility to allow students with disabilities alternative modes of accessing the campus environment and demonstrating competency. Most schools have designated a disability office or individual Disability Resource Professional (DRP) to work to ensure the campus and/or the programs are fully accessible to students with disabilities (see Chapter 1).

\section{WHAT IS A DISABILITY UNDER THE AMERICANS WITH DISABILITIES ACT?}

The ADA defines a disability as a physical or mental impairment that substantially limits one or more major life activities, a record of such an impairment, or being regarded as having such an impairment. ${ }^{6}$ The law expressly states, "An impairment that is episodic or in remission is a disability if it would substantially limit a major life activity when active." ${ }^{\prime 7}$ To qualify as a disability, an impairment does not need to be a permanent condition but must last a substantial amount of time. ${ }^{8}$ Further, a condition might substantially limit a major life activity and therefore constitute a disability, even if the individual uses "mitigating measures," such as auxiliary aids or medication. ${ }^{9}$ For example, a person who is able to walk but relies on the assistance of a cane is still a person with a disability because the major life activity of walking is affected. To receive disability accommodations, the law requires not only that a person have a medical condition, but that this condition "substantially limits" a major life activity. The limitation must go beyond a nuisance to rise to the level of being disabling. "Major life activities" include breathing, walking, talking, hearing, seeing, eating, learning, reading, concentrating, and thinking. ${ }^{10}$ The ADAAA also expressly includes impairments of major bodily functions and systems (e.g., digestive, neurological, endocrine), making clear that individuals with chronic health conditions or diseases, such as diabetes or cancer, are covered by the ADA's disability protections.

As mentioned, the ADA's definition of disability also includes those who "have a record of" or are "regarded as" an individual with a disability. ${ }^{11} \mathrm{~A}$ student with "a record of" having a disability is one who has a history of having a disability, even if it is no longer present or does not substantially limit a major life activity. For example, the federal government has asserted that students with hepatitis $B$ are individuals with disabilities who should be allowed full participation without restriction in most dental and medical programs

\footnotetext{
${ }^{6} 42$ U.S.C. $\S 12102(1)$.

${ }^{7} 42$ U.S.C. $\S 12102(4)(\mathrm{D})$.

${ }^{8} 42$ U.S.C. § $12102(3)(B)$.

${ }^{9} 42$ U.S.C. $\S 12102(4)(\mathrm{E})(\mathrm{i})$.

${ }^{10} 42$ U.S.C. $\S 12102(2)(A)$.

${ }^{11} 42$ U.S.C. § 12102(1).
} 
(DOJ, HHS, \& DOE, 2013). An individual who is "regarded as" a person with a disability is someone who does not have a condition that substantially limits a major life activity but due to appearance (e.g., visible surgery scars or a medical record that includes a history of a condition or disease no longer present) is assumed by others to have a disability. In either case, the individual is typically not entitled to disability accommodations on the basis of that condition alone, if it does not substantially limit a major life activity. However, individuals who have a record of disability or who are regarded as having a disability could sue for discrimination under the ADA if they were treated in a discriminatory manner because someone assumed a disabling condition was present (see Scenario 2.1).

Because of the complexity of the law and its associated protections, it is important not to allow accommodations to be determined and provided by faculty or others alone- even those with the best of intentions - in the absence of a student request, careful review of medical documentation, and approval of appropriate accommodations by a trained disability professional. This will be discussed in detail in Chapter 4 and Chapter 5.

\section{Definitions of a Disability Under State Laws}

It is important to note that some states have their own disability laws and may have a definition of disability that differs from the federal ADA definition just described. For example, whereas the federal government defines a disability as a substantial limitation of a major life activity, California state law states that a disability must merely "limit" — not "substantially limit"—a major life activity, making more individuals entitled to disability accommodations in

\section{SCENARIO 2.1 "Regarded as" an Individual With a Disability}

A student has extensive burn scars on his or her face and arms, but the scars do not impose any functional limitations, nor has the student requested any accommodations with regard to that condition. Although the student can perform all of the required tasks at the same level as his or her peers, the clinical director assigns him or her to a less desirable clinical rotation because he or she (unreasonably) believes that the student's appearance will make him or her less effective and therefore negatively reflect on the school. The director wants to avoid harming the school's relationship with the more prestigious clinical locations. This student may win a lawsuit against the school under the ADA for disability discrimination, even though he or she is not a student with a disability who required accommodations in the clinical setting. 
the state. ${ }^{12}$ Although some states may have disability laws that allow broader disability accommodations than the federal government, other states may have more restrictive- or no-state law governing disability accommodations. In states with their own disability rights laws, the law that provides the most protection for individuals with disabilities-whether federal or state law-must guide decision-making in that state. Where there is no state disability rights law, the ADA is the relevant law to follow.

Due to the variations in laws at the state level, this book will refer only to federal law, with which residents of all states must be familiar. Faculty and DRPs should consult with their school's legal counsel to ensure appropriate compliance with federal, state, and local disability laws.

\section{DISABILITIES IN THE EDUCATIONAL ENVIRONMENT}

To be considered a disability requiring accommodations in the college environment, the medical condition must not only substantially limit a major life activity, but the affected activity must be related to the student's functioning in the campus environment, including all aspects of that environment (e.g., academics, housing, transportation, parking, extracurricular activities, and dining services). This is important because there may be students on campus who have a disability as defined by the ADA, but who do not need any disability accommodations to have equal access to the school's programs and activities.

\section{Students With Disabilities Must Be "Otherwise Qualified" for the Educational Program}

Section 504 states that no "otherwise qualified" person with a disability may be excluded from participation in any program that receives federal funds. Many cases have held that if a student cannot pass, even with all appropriate accommodations fully implemented, they are not otherwise qualified for the program. ${ }^{13}$ However, the student must be given a full opportunity to pass; a school cannot determine that a student who is currently passing but the school believes is likely to fail in the future is not otherwise qualified. ${ }^{14}$

What constitutes being "otherwise qualified" depends on the type of program at issue. For open enrollment programs with no admissions criteria, "otherwise qualified" means that the students merely meet the program's stated criteria for participation, such as age, residency, and so forth, and are able to successfully complete the coursework. For programs that require admission,

\footnotetext{
${ }^{12}$ Cal. Gov't Code § 12926.1(c).

${ }^{13}$ See, for example, Chin v. Rutgers University School of Medicine, Case No. 16-2737. (3rd Cir. 2017); Zukle v. Regents of the University of California, 166 F.3d 1041 (9th Cir. 1999); Wynne v. Tufts University School of Medicine, 976 F.2d 791 (1st Cir. 1992); Wong v. Regents of the University of California, 192 F.3d 807 (9th Cir. 1999).

${ }^{14}$ Hill v. George Fox University, Case No. 3:2015cv01148 (D.Ore. 2017).
} 
meeting the admissions standards and maintaining passing grades once admitted typically indicates that candidates are "otherwise qualified" to be in the program. For programs with technical standards, individuals must not only meet the academic requirements, but also meet the technical standards to be considered "otherwise qualified." See Chapter 3 for a detailed discussion about technical standards.

\section{THE PROCESS FOR DETERMINING ACCOMMODATIONS}

\section{A Two-Step Inquiry}

For purposes of explanation, this book breaks the accommodations determination process into two discrete inquiries:

1. Is there a qualifying disability?

2. If so, what accommodations may be appropriate?

This distinction is a bit artificial in daily practice; in work with students, these two questions are often addressed simultaneously. Nonetheless, splitting the process into two distinct spheres allows a clearer explanation. This chapter will address question one, and Chapter 4 will address the second question.

\section{Creating a Standard Procedure for Accommodations-and Following It-ls Important}

When reviewing disability accommodations decisions made by institutions, courts and the Office for Civil Rights (OCR) look primarily at whether the school followed proper procedures when making decisions. If the procedure was proper and all of the relevant people were included in the decision-making process, generally the court or OCR will defer to the institution's decision. ${ }^{15}$ However, if the decision was made with an insufficient interactive process, the court or OCR tends to reject the school's decision or at least require further consideration of the student's accommodation request. ${ }^{16}$ No matter what the request from the student, a school must always go through a legitimate process of considering it, and not reject it out of hand. However, the student must not fail to participate. If a student is aware of procedures for requesting accommodations but fails to follow them, the school is not liable for failing to accommodate. ${ }^{17}$

\footnotetext{
${ }^{15}$ Zukle v. Regents of the University of California, 166 F.3d 1041 (9th Cir. 1999); Guckenberger v. Boston University 974 F.Supp. 106 (D.Mass. 1998); McCulley v. The University of Kansas School of Medicine, No. 13-3299 (10th Cir. 2014). ${ }^{16}$ Wynne v. Tufts University School of Medicine, 976 F.2d 791 (1 ${ }^{\text {st }}$ Cir. 1992); Wong v. Regents of the University of California, 192 F.3d 807 (9th Cir. 1999).

${ }^{17}$ Buescher v. Baldwin Wallace University, No. 1:13 CV 2821 (N.D. Ohio 2015).
} 
To determine whether a condition substantially limits a major life activity that affects the student in the academic environment and, subsequently, whether it requires disability accommodations in the educational setting, the DRP must gather and review the student's relevant documentation. Documentation includes subjective information from the student about past experiences with the disability and any prior accommodations received, the DRP's own observations, and written verification of disability from a third party. All of that documentation taken together will help the school evaluate whether a student's condition rises to the level of a disability requiring academic accommodations under the law.

\section{Intake Interview With the Student}

The most important part of the documentation process is the student interview. Specific information about the effects of an individual's disability on educational activities can only be obtained from the student. During the process of determining disability and reasonable accommodations, students should be invited to describe:

- how the condition affects them in and out of the classroom;

- personal history of academic difficulties,

- personal history of receiving accommodations, if any, and

- any strategies used to facilitate participation and functioning in and out of the classroom.

The leading professional organization for DRPs, the Association of Higher Education and Disability (AHEAD), has created a useful interview guide, which includes sample questions for eliciting relevant information (Meyer, Thornton, \& Funckes, n.d.).

\section{Written Documentation From Healthcare Providers or Other Third Parties}

The ADA does not require that students provide their school with written documentation from a doctor or other care provider or results of evaluative measures, such as psych-educational testing for learning disabilities (LD), in order to obtain accommodations. Nonetheless, most health science programs require most students seeking accommodations to provide at least some thirdparty verification of disability (with the exception of some readily apparent disabilities, for which documentation may be unnecessary). The reasons for this vary by school but often include ensuring uniformity of requirements among students, attempting to be consistent with board exam requirements (nearly all health science board exams require some third-party disability verification), and, in some states, disability office audit requirements. As described further, schools may require documentation, as long as it is not overly burdensome and documentation requirements are applied uniformly. 


\section{Types of Third-Party Documentation That May Be Required}

The type of third-party documentation sufficient to establish the presence of a disability depends on the disability type. A healthcare provider who has a relationship with the student and is sufficiently trained to provide an expert opinion on the diagnosis, as well as details about the student's functional limitations, should provide documentation. Third-party documentation should clearly describe how the student's condition limits a major life activity related to the educational environment. It should include a description not only of symptoms directly related to the underlying condition, but also the side effects of any necessary medication.

The third-party documentation verifying a student's disability should be in writing. Most schools have a standard form for healthcare providers to complete (see Sample Disability Verification Form, Appendix 2.1) and will also accept a letter on the provider's letterhead if it provides all of the relevant information. One exception is the outside documentation necessary for LD. Diagnosis of LD typically requires extensive testing, typically summarized in a lengthy report, although some circumstances may dictate more leniency in the assessment and its summary. See Practice Recommendation 2.1.

\section{Practice Recommendation 2.1 What If a Student Does Not Have a Comprehensive LD Evaluation?}

Historically, if a student's LD evaluation was not fully comprehensive, the school might insist on a much more extensive evaluation before accommodations would be determined and implemented. Although it is true that an assessment with comprehensive evaluation components and processes provides the most complete assessment, the 2008 ADA Amendments Act put a much greater emphasis on a student's history of having received accommodations as an indicator that future accommodations are needed. ${ }^{18}$ Therefore, a student who has had only a partial evaluation should not be forced to undergo a full neuropsychological or psychoeducational assessment before accommodations are implemented. Despite the use of partial documentation for approval of accommodations in the program, students must be cautioned that some board exam organizations, like the National Board of Medical Examiners (NBME) still require an indepth and 3-year current evaluation before reviewing a request for accommodations. Therefore, students may still need to get a comprehensive psych-ed evaluation before applying for accommodations from these testing entities. Note that OCR has said schools may not create their standards based solely on the licensing exams' more stringent requirements. ${ }^{19}$

${ }^{18}$ ADA Amendments Act of 2008, PL 110-325 (S 3406) (September 25, 2008).

${ }^{19}$ OCR Letter to John Wood Community College, Case No. 05-18-2040 (2018). 
The third-party documentation requirements of each school may vary. For example, a few schools require psychoeducational testing results to verify a diagnosis of attention deficit hyperactivity disorder (ADHD), whereas many will accept a psychologist's or psychiatrist's written assertion that ADHD is present, based on the professional's clinical judgment combined with student self-report. However, an institution is not obligated to merely accept a student's self-diagnosis, without any third-party documentation. OCR has established that schools have the right to request formal verification of a disability from a healthcare provider. ${ }^{20}$

OCR has also determined that documentation from a healthcare provider should primarily be relied upon to determine whether a student has a disability and requires accommodations, but it should not dictate what the specific accommodations are. ${ }^{21}$ The information in such third-party documentation may help inform what accommodations may be appropriate, but institutions may not limit a student's accommodations to those specifically listed by a medical professional.

Each institution should determine what, if any, written medical documentation it will require, clearly define its documentation requirements in writing, and apply those standards equally to all students. A useful guide regarding third-party documentation comes from AHEAD (AHEAD, 2012). See Table 2.1 for general descriptions of the third-party documentation most commonly required for the broad categories of disability and Practice Recommendation 2.2 for guidance about its contents.

\section{Table 2.1 Disability Categories and Typical Third-Party Documentation}

\section{DISABILITY CATEGORY THIRD-PARTY DOCUMENTATION TYPICALLY NECESSARY}

\begin{tabular}{l} 
Learning disability \\
$\begin{array}{l}\text { Psychoeducational testing report written by a qualified } \\
\text { professional with expertise in learning disabilities, training in } \\
\text { administering the tests used, and experience working with adults, } \\
\text { such as a licensed educational psychologist, clinical psychologist, } \\
\text { or learning disabilities specialist }\end{array}$ \\
\hline
\end{tabular}

\begin{tabular}{ll}
\hline Hearing disability & $\begin{array}{l}\text { Audiology report or letter from an audiologist verifying the } \\
\text { extent of hearing loss }\end{array}$
\end{tabular}

Vision disability Form or letter provided by a treating physician describing the type and extent of the vision limitations

(continued)

${ }^{20}$ OCR Letter to Pasadena City College, Case No 09-14-2356 (2015).

${ }^{21}$ OCR Letter to Kellogg Community College, Case No. 15-15-2017 (2015). 


\section{Table 2.1 Disability Categories and Typical Third-Party Documentation (continued)}

\section{DISABILITY CATEGORY THIRD-PARTY DOCUMENTATION TYPICALLY NECESSARY}

\begin{tabular}{ll}
\hline $\begin{array}{l}\text { Attention deficit hyperactivity } \\
\text { disorder (ADHD) }\end{array}$ & $\begin{array}{l}\text { Psychoeducational testing report (see learning disability } \\
\text { requirements), form, or written assessment from a treating } \\
\text { professional (generally a psychologist or psychiatrist) verifying } \\
\text { the diagnosis and describing how the symptoms substantially } \\
\text { limit a major life activity }\end{array}$ \\
\hline Psychological disability & $\begin{array}{l}\text { Form or letter from a treating professional verifying the diagnosis } \\
\text { and describing how the symptoms substantially limit a major life } \\
\text { activity }\end{array}$ \\
\hline Physical/mobility disability & $\begin{array}{l}\text { Form or letter from a treating professional verifying the diagnosis } \\
\text { and describing how the symptoms substantially limit a major life } \\
\text { activity }\end{array}$ \\
\hline
\end{tabular}

\section{Readily Apparent Disabilities}

If a disability can be clearly observed, there is no need to require third-party documentation verifying the disability. However, if a student with an observable disability is requesting accommodations for any nonobservable aspect of the disability, then it may be appropriate to request outside documentation verifying the functional limitations imposed by the disability. Students can be asked to provide third-party documentation where the disability is not open, obvious, and apparent. ${ }^{22}$

\section{Third-Party Documentation Should Be Current}

Third-party documentation should not be so old that it fails to reflect the student's current level of functioning. This typically means that the documentation should be recent enough to reflect the student's functioning as an adult, using adult-normed measurements. There are limited situations in which older medical documentation may be acceptable, such as when the condition has been stable for a significant period of time. In that case, a recent note from the student's healthcare professional verifying that the older documentation still reflects current functioning may be requested. Students relying on older documentation should be made aware that although the school may accept it,

${ }^{22}$ Doan v. Board of Supervisors of Louisiana State University, et al., Case No. 17-3471 (E.D. La., 2017). 


\section{Practice Recommendation 2.2 Third-Party Documentation Standards}

If requesting third-party documentation, it should:

- identify the condition with specificity,

- be from a qualified medical professional who had direct experience with the student, and

- include information about all disabilities for which accommodations are sought.

certain licensing or certification boards may require more recent documentation before providing accommodations on their exams (see Chapter 6).

\section{Cost of Obtaining Third-Party Documentation}

Students can legally be made responsible for bearing the cost of any medical appointment or evaluation necessary to document the existence of a disability, however, for equity and convenience reasons, some schools offer evaluations or testing to students free of charge or at a reduced rate. There is no legal obligation for a school to cover the cost of obtaining documentation; however, there are a number of ways schools can facilitate students' obtaining an evaluation from an outside entity. The cost of evaluations may be rolled into student loans (it is an educational expense). Some schools have emergency grant or loan programs in place for low-income students who face unexpected personal or educational expenses. DRPs may want to collaborate with the financial aid office to offer supports to help students cover the costs of an outside evaluation. At institutions that offer student health insurance, the benefits may cover psych-ed assessments. For schools whose student health insurance plan does not cover them, DRPs may also work with their school's health insurance committee to advocate for added benefits to cover psych-ed evaluations, or the health science programs might consider developing a stipend to cover the costs in full or in part for students enrolled in that program. Health science programs in particular may have a particular interest in ensuring students are able to obtain adequate evaluations for certification or licensing board exam accommodations, especially when these exams are used for promotion within the program.

\section{Disability Verification Form}

Most schools have a verification form available for treating professionals to use for documenting a student's disability. This form provides guidance regarding the information deemed necessary by the institution (see Appendix 2.1 for a sample form). Generally, such a form includes the following elements:

- Credentials of the person completing the form and relationship to the student. 
- Student's diagnosis(es), including severity and predicted course.

- Procedures/assessments used to diagnose the condition.

- The extent and degree to which the condition interferes with a major life activity.

- How the condition (and/or current treatment) impacts the student's ability to function in the school environment.

- Any accommodations that the healthcare professional believes are necessary to provide the student access to the institution's programs, activities, and services (a school is not obligated to do what the professional recommends, but this step can help identify potential needs).

- Permission from the student for disability office personnel to speak directly to the person who provided the documentation to clarify the disability-related barriers, if necessary.

Limits on Third-Party Disability Documentation Requests: Written documentation of disability should be sufficient to establish a need for accommodations, but it cannot be overly burdensome for a student to obtain. If the documentation initially provided by a student does not contain sufficient information to adequately assess the student's disability-related barriers, it is appropriate to request additional documentation (see Case Example 2.1). However, a school cannot request that a student provide documentation of disability beyond an amount that is reasonable (see Case Example 2.2).

\section{CASE EXAMPLE 2.1 Kaltenberger v. Ohio College of Podiatric Medicine ${ }^{23}$}

A student struggling in classes underwent testing at her university to determine if ADHD was present; the testing concluded that there was no clear evidence that the student had ADHD. A few months later, she provided the university with a short, hand-written note from a physician stating that she had been under an MD's care for ADHD for the last 3 weeks and together they were "trying different medications." The note did not include information regarding the basis for the diagnosis, nor did it indicate the doctor's credentials for diagnosing ADHD; therefore, the university informed the student the note was insufficient to establish that he or she has a disability. The student sued the university for disability discrimination after she was ultimately dismissed from the school due to low grades. The court held that it was reasonable for the university to have required more documentation than one short doctor's note to establish the presence of ADHD and the need for accommodations.

${ }^{23}$ Kaltenberger v. Ohio College of Podiatric Medicine, 162 F. $3 d 432$ (6th Cir. 1998). 


\section{CASE EXAMPLE 2.2 Abdo V. University of Vermont ${ }^{24}$}

A student provided letters from doctors confirming that she had been in automobile accidents and detailing the physical limitations that resulted. The university said that it needed more documentation because the letters did not state a particular diagnosis and refused to provide the disability accommodations requested by the student and recommended by her physicians in the letters. The student sued the school, alleging disability discrimination, and the court agreed with the student that the university's requirement that students obtain and present to the university a formal diagnosis in order to receive accommodations was not legal because it was unnecessarily burdensome. The court held that the thorough descriptions of the physical limitations included in the student's medical documentation constituted sufficient evidence of disability, even without the label a diagnosis provides.

${ }^{24}$ Abdo v. University of Vermont, 263 F.Supp.2d 772 (D.Vt. 2003).

\section{MAKING THE DISABILITY DETERMINATION}

On its own, a diagnosis does not automatically mean a disability is present. Once all of the relevant information from healthcare providers and the student has been gathered, the DRP must determine whether the condition interferes with a major life activity affecting the student in the educational environment. If not, it is not a disability, and no accommodations are needed. It is good practice to include a question on the form completed by the treating professional that asks whether the condition interferes with a major life activity, and, if yes, to explain the activity and how it is affected. This assists the school personnel in making that determination.

It is also important for the DRP making the determination regarding whether the student has a disability to make sufficient notes documenting the decision-making process, so that if the decision is later questioned, the DRP's reasoning is clear. See Practice Recommendation 2.3 for a description of the process of reviewing documentation and determining whether a student has a disability as defined by the ADA, for schools that require third-party documentation.

\section{CONDITIONAL ACCOMMODATIONS}

Occasionally it may be appropriate to implement accommodations on a conditional basis, particularly where information is not fully available or time is a factor. For example, if a student is in the process of acquiring third-party documentation or is undergoing an evaluation that is not yet complete and the DRP is fairly confident the disability will be documented in the near future, it may be appropriate to go ahead and implement accommodations, particularly 
Practice Recommendation 2.3 Process of Reviewing Documentation and Determining Whether a Student Has a Disability as Defined by the ADA

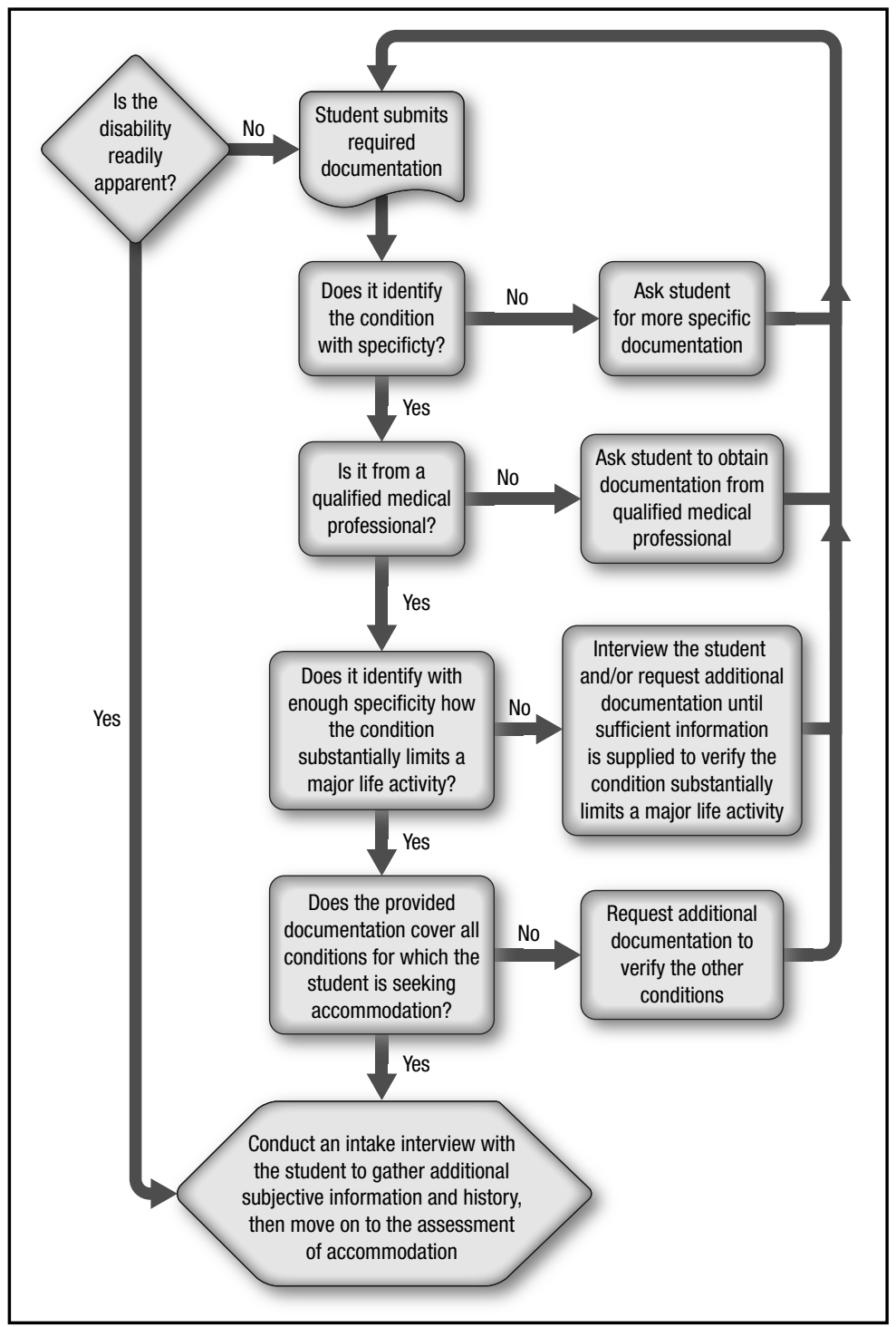

Continue to the second Howchart, Determining Appropriate Accommodations, in Chapter 4. 
if there is an impending exam or other event for which having accommodations in place could "make or break" the student's outcome. Another occasion for conditional accommodations could occur if a student is (or very recently was) in crisis. Implementing accommodations immediately can allow some "breathing room" supports until the student's condition is more stable. Once the crisis has passed, a fuller assessment can be made. Conditional accommodations are often particularly critical in lockstep programs, where the consequence is not just failing one course, but stepping out of the program, which will also frequently cause the loss of time-to-degree, financial aid, and the cohort supports a student has developed with peers. Caution should be used in implementing conditional accommodations, however; if it is later determined that a student is unable to verify any disability, it can be difficult to remove accommodations that a student has been using.

\section{TEMPORARY DISABILITIES}

The ADAAA, passed in 2008, expanded the ADA's legal obligation for a university to accommodate students with temporary disabilities, although it is not specific about how long a disability must last to qualify. Courts have begun to rule in accordance, holding that an individual with a temporary disability is not necessarily excluded from the ADA's protections..$^{25}$ Although this is a fairly recent legal obligation, it has long been common for schools to provide temporary accommodations to students who acquire a short-term disabling condition, often due to injury or surgery, even if not mandated by law. It is recommended practice that all temporary disability accommodations be handled through the disability office with associated documentation of steps taken to remove barriers. This way, should the condition extend to permanent status, all interaction between the student and the institution is documented.

\section{Documenting Temporary Disabilities}

The documentation requirements for a temporary disability may be less rigorous for example, a note from a healthcare professional verifying the injury or surgery is usually sufficient. The verification for a temporary disability should include an anticipated end date, so that a student does not continue to receive accommodations beyond the time they are no longer needed. If the anticipated recovery date is later postponed due to a change in the student's recovery prognosis, an updated note from the provider should be requested and kept on file.

\section{Pregnancy}

Pregnancy is not typically considered a disability under the ADA; however, if medical complications from pregnancy arise, the student might become

\footnotetext{
${ }^{25}$ Summers v. Altarium Institute, 730 F.3d 325 (4th Cir. 2014).
} 
entitled to accommodations under disability law. In either case, Title IX protections apply to women who are pregnant or who recently gave birth. ${ }^{26}$ Whether the disability office or the Title IX office (or another campus office) oversees pregnancy accommodations varies by school. Each school should identify a particular office and establish how it will evaluate and accommodate needs related to pregnancy and/or complications arising from pregnancy.

\section{OBLIGATIONS OF THE STUDENT AND THE SCHOOL}

\section{Notification of Disability and Accommodation Request Process}

It is the student's obligation to follow the school's published procedures for submitting and requesting accommodations. Students cannot expect that accommodations will be provided if they do not comply with the procedure for requesting accommodations. OCR and courts have repeatedly agreed, finding in favor of the school in cases in which a student did not follow the steps required to obtain accommodations. ${ }^{27}$

However, the school must make reasonable efforts to make students aware of the disability office procedures (see Practice Recommendation 2.4). If students are not sufficiently informed about the process for requesting accommodations, OCR has held that the student is not accountable for failing to fulfill them. ${ }^{28}$

\section{Practice Recommendation 2.4 Ensuring Visibility of the Disability Office}

Make sure students at your institution know about the student disability office by ensuring each of the following:

- The disability office procedures and forms are readily available online.

- Students are informed about the office and what it does during orientations in each department (a short presentation by disability office staff allows new students to get to know service providers).

- Written information about the disability office is included in the acceptance or registration documents sent to students prior to attending.

(continued)

\footnotetext{
${ }^{26}$ Title IX of the Education Amendments of 1972, 20 U.S.C. $§ 1681$, et seq.

${ }^{27}$ Chenari v. George Washington University, 847 F.3d 740 (D.C.Cir 2017); Buescher v. Baldwin Wallace University, No. 1:13 CV 2821 (N.D. Ohio 2015); OCR Letter to Florida Southwestern State College, No. 04-16-2161 (2016); OCR Letter to College of Saint Rose, Case No. 02-00-2055 (2001); OCR Letter to Texas Woman's University, Case No. 06-00-2038 (2000); OCR Letter to Western Michigan University, Case No. 15-99-2016 (2000); OCR Letter to A.T. Still University, Case No. 07-09-2017 (2009).

${ }^{28}$ OCR Letter to Concord Career Institute, Case No. 09-05-2022 (2005).
} 


\section{Practice Recommendation 2.4 Ensuring Visibility of the Disability Office (continued)}

- Faculty members are provided with standard lansuase to include on their syllabi that describes how to obtain accommodations and encourases any students who think they may have a disability to visit the disability office.

Making these practices standard not only helps ensure that no student can ever say, "I didn't seek accommodations because I didn't know there was a disability office for students on campus," but it also has the effect of normalizing the presence of disabilities on campus by making nondisabled students aware that students with disabilities are in their midst, even if the disabilities are not readily visible.

\section{Confidentiality of Students' Medical Documentation}

Health science students are frequently concerned about who will know about their disability and who will have access to their records. As future medical professionals, students understandably want to know whether their documentation could be used against them in a future career (e.g., inability to get malpractice insurance, inability to get licensed, concern with malpractice lawsuits having access to documentation), and also have general concerns regarding the privacy of their sensitive information.

The Family Educational Rights and Privacy Act (FERPA) is a federal law that requires schools to protect students' educational records, including the documentation that students submit to verify a disability, as well as the other portions of a student's disability file..$^{29}$ Generally, schools must have written permission from the student in order to release any information from a student's educational records beyond what would be considered directory information, such as name and contact information. However, FERPA lists a few categories of employees who may be privy to students' private academic records-even without written consent-in limited circumstances, including school officials and faculty with legitimate educational interest or in health and safety emergencies. ${ }^{30}$

It is important to emphasize that because the disability office is not a healthcare provider, any documentation of a student's disability that is maintained by the office is considered an educational record and is therefore not afforded protection under the Health Insurance Portability and Accountability Act (HIPAA) of $1996 .{ }^{31}$ (See Chapter 8).

\footnotetext{
${ }^{29} 20$ U.S.C. $\S 1232 \mathrm{~g}$.

${ }^{30} 34$ C.F.R. $\S 99.31$.

${ }^{31} 42$ U.S.C. $§ 1320$ d-5 \& 6; 45 C.F.R. $\S \S 160$ \& 164.
} 
Although they are not legally required to do so, many disability offices opt to maintain stricter confidentiality than is legally required and do not release information to faculty without written permission from the student. However, a disability office should not guarantee complete confidentiality to students; DRPs could be required to disclose a student's disability information in some limited circumstances, such as in the case of an emergency or if compelled in the course of litigation (see Case Example 2.3). The office should make its policy regarding when disability-related information may be released very clear, and then stick to the published policy uniformly. See Practice Recommendation 2.5 for tips on maintaining the confidentiality of documents.

\section{CASE EXAMPLE 2.3 Tecza v. University of San Francisco ${ }^{32}$}

A school's disability office handbook promised students complete confidentiality regarding all information pertaining to disability. Later, other students were accidentally permitted to see information about a disabled student's accommodations, and the student sued the university for, among other reasons, breach of contract for violating the promise of confidentiality contained in the disability office handbook. The court held that a student may sue for breach of contract when a school fails to uphold the level of confidentiality promised.

${ }^{32}$ Tecza v. University of San Francisco, 532 Fed. Appx. 667 (9th Cir. 2013).

\section{Practice Recommendation 2.5 Maintaining Confidentiality of Documents}

- Shred any paper created in the office on which private information-even just a student name-is written, including sticky notes or phone message slips. Never put those in trash or recycling bins.

- If the institution has a mechanism for encrypting e-mail or electronic records, use it for electronic communications that contain student names or disability information.

- Keep student names and disability information out of email subject lines, which are not included in encrypted or secure systems and may be viewed on a computer screen by visitors to an office.

- Keep the office fax machine in a place where others cannot access it.

- Keep paper files locked when not immediately using them.

- Do not transport paper files to insecure locations.

- Password protect electronic records and limit the access to necessary staff.

- Keep electronic records "walled off" from access by other campus departments that may share the server or other online access. 


\section{Readmission Requirements and Limitations}

Sometimes students decide they need to take a leave of absence after a flare of symptoms or a new diagnosis. At times, particularly for mental health disabilities, the leave of absence was preceded by a period when the student exhibited behavior the school deemed concerning or the third-party documentation provided for purposes of a leave of absence raised concerns. In these cases, some schools have attempted to impose mental health assessments to "clear" a student for return. Schools, however, should use caution in imposing such readmission requirements. The ADA prevents schools from imposing eligibility or screening requirements that "screen out or tend to screen out an individual with a disability or any class of individuals with disabilities from fully and equally enjoying any goods, services, facilities, privileges, advantages, or accommodations, unless such criteria can be shown to be necessary for the provision of the goods, services, facilities, privileges, advantages, or accommodations being offered." ${ }^{33}$ Accordingly, an institution may only legally require a mental health assessment as a prerequisite to allow a student to attend if there is a valid, realistic threat posed by the student. For example, OCR has held that a school cannot ask a student who was suspended for a drug violation to undergo a psychiatric assessment before allowing the student back on campus, unless the school first conducts a direct-threat analysis and concludes that the student poses a significant risk to the health and safety of others on campus. ${ }^{34}$

Wellness contracts are another matter that requires caution. The courts have held that requiring students to enter into a behavior or wellness contract as a condition of returning to school following a hospitalization may be a violation of their rights. For example, one school's contract required that a student get a certain amount of sleep, not cry during class, and no longer serve as student body vice president, among other requirements. The student filed a complaint with the OCR, which held that the school must stop requiring students to abide by such "wellness contracts." After the school failed to abide by the OCR's decision, the student filed a lawsuit and the court allowed the disability discrimination lawsuit to go forward. ${ }^{35}$ However, if a student exhibits behavior that legitimately threatens the health or safety of others, the OCR has held that a school may require that a student undergo a mental health evaluation before readmission is allowed. ${ }^{36}$ It is important to remember that schools can only require a mental health evaluation before readmission in cases where a student shows a direct threat to others-otherwise readmission policies for students with disabilities must be the same as for nondisabled students. ${ }^{37}$

\footnotetext{
${ }^{33} 42$ U.S.C. $\S 12182(\mathrm{~b})(2)(\mathrm{A})(\mathrm{i})$.

${ }^{34}$ OCR Letter to Keystone College, Case No. 03-09-2027 (2009).

${ }^{35}$ Larson v. Snow College, 115 F. Supp. 2d 1296 (D.Utah 2000).

${ }^{36}$ OCR Letter to Regent University, Case No. 11-03-2022 (2003).

${ }^{37}$ OCR Letter to Western Michigan University, Case No. 05-13-2038 (2013).
} 


\section{CONCLUSION}

Understanding the relevant disability laws and staying abreast of recent cases will ensure that DRPs, faculty, and staff conduct their work in a manner that upholds the academic standards of the institution while honoring the spirit and intent of the legislation-to ensure the full participation of people with disabilities in the educational environment. Once the responsible administrator has determined that the student meets criteria for being recognized as a student with a disability, the next step is to determine what, if any, accommodations are needed. Chapter 4 reviews the interactive process for determining accommodations once disability eligibility is met.

\section{REFERENCES}

Association of Higher Education and Disability. (2012, October). Supporting accommodation requests: Guidance on documentation practices. Huntersville, NC: Association on Higher Education and Disability. https://www.ahead.org/ professional-resources/accommodations/documentation

Finkelstein, V. (1993). The commonality of disability. In J. Swain, V. Finkelstein, S. French, and M. Oliver (Eds.), Disabling barriers, enabling environments (pp. 9-16). London, England: Sage.

Goodley, D. (2017). Disability studies: An interdisciplinary introduction. London, England: Sage.

Joint Dear Colleague Letter from Acting Assistant Secretary for the Office for Civil Rights Seth Galanter, Principal Deputy Assistant Attorney General for the Civil Rights Division Jocelyn Samuels, and Director of the Office for Civil Rights Leon Rodriguez, U.S. Departments of Education, Justice, and Health and Human Services (2013, June 12).

Meyer, A., Thornton, M., Funckes, C. (n.d.). The professional's guide to exploring and facilitating access. Association on Higher Education and Disability. https:// www.ahead.org/professional-resources/accommodations/documentation/ professional-resources-accommodations-professional-guide-access

Oliver, M. (1996). Understanding disability: From theory to practice. New York, NY: St. Martin's Press. 


\section{APPENDIX 2.1 SAMPLE VERIFICATION OF DISABILITY FORM}

Student Name: Birth date:

I am requesting disability accommodations through the [NAME OF DISABILITY OFFICE] at [NAME OF SCHOOL/UNIVERSITY]. The school requires current and comprehensive documentation of my disability/medical condition as one of the criteria used to evaluate my eligibility for disability-related accommodations. Please respond to the following questions as soon as possible and return to me or send to the disability office by mail or fax. I authorize the disability office to contact you if clarification is needed.

Student Signature: Date:

Healthcare provider name (print):

Title: Phone: Fax:

Organization and address:

The following area must be completed by the healthcare professional listed on this page.

1. Diagnosis(es) and date(s):

2. Current status of condition(s) (e.g., active, progressing, controlled, in remission): 
3. Current level of severity (choose one): Mild Moderate Severe

4. How long is this condition(s) likely to persist (be as specific as possiblee.g., lifetime; 1 academic year; duration of academic program enrollment; 1 month):

5. Please list procedures/assessments used to diagnose this student's condition:

6. What are the functional limitations or symptoms of the condition(s)?

7. What exacerbates this student's specific disability(ies)? (Please be as specific and detailed as possible) 
8. How does the condition (and/or current treatment) impact the student's ability to learn or meet the demands of the university setting, clinical requirements, and/or ability to live in university housing?

9. Identify any accommodations you believe may be necessary in order for the student to participate in the university's programs, activities, and services:

This information is current and accurate to the best of my knowledge based on my recent evaluation of this patient or my review of records of a recent evaluation by a qualified healthcare provider.

Signature of Treatment Provider

License \#

Date

Thank you for your cooperation. You may fax or email your report to the [office name] at [FAX NUMBER]. Please call [PHONE NUMBER] if you require additional information. Please attach any additional reports or relevant information. All information on this form will remain confidential in accordance with the Family Educational Rights and Privacy Act (FERPA). 